\title{
SECONDARY ASSOCIATION BETWEEN GENETICALLY EQUIVALENT BIVALENTS
}

\author{
C. KEMPANNA and RALPH RILEY \\ Plant Breeding Institute, Combridge
}

Received I 2.xii.63

\section{INTRODUCTION}

THE occurrence of bivalents in pairs or groups rather than at random, at first metaphase of meiosis in a number of polyploid plant species, has been described by several authors (Darlington and Moffet, I930; Lawrence, 1931; Sakai, 1935; Nandi, 1936), and called secondary association. It was ascribed by Darlington and Moffet and by Lawrence to attractions that developed between genetically and structurally similar chromosomes, analagous to those resulting in prophase synapsis. The bivalents participating were considered to be composed of chromosomes more distantly related than those between which primary pairing and chiasma formation takes place.

Other authors have disagreed with the explanation based on the residual homology of the participants and have ascribed secondary association to terminal affinities and to the fusion of the pellicles of chromosomes (Gustafsson, I934), or to the differential operation of forces of repulsion upon bivalents of different sizes (Heilborn, 1936). Thomas and Revell (1946), from the analysis of synthetic autopolyploids, concluded that secondary association was principally between homologous chromsomes but claimed that it was the result of heterochromatic fusions, at pachytene, between chromosomes in adjacent bivalents that were potentially capable of quadrivalent formation.

However, a rigorous analysis of the relationships of the bivalents that were secondarily associated was not possible in a natural polyploid until material became available in the allohexaploid common wheat (Triticum astivum $(2 n=42)$ ). By the use of this material any two bivalents could be simultaneously marked by a structural condition, and their relative positions observed at first metaphase. T. astivum provides ideal material for this purpose since it regularly forms $2 \mathrm{I}$ bivalents of approximately equal size, at meiosis, and because its $2 \mathrm{I}$ haploid chromosomes have been classified into three genomes each of seven chromosomes and into the seven groups each of three genetically equivalent chromosomes-one in each genome. Thus it is possible to compare the relative spacings of genetically related or unrelated bivalents. Moreover, there is some indication of the occurrence of secondary association since at first metaphase bivalents can be observed close together in groups of three, although separate groups are widely spaced (plate I, fig. I).

Riley (196oa) used these advantages and showed that when two T 2 
genetically equivalent bivalents were cytologically marked they were found to be immediately adjacent more frequently than would have been so if their positioning had been independent. Thus there is evidence in favour of the occurrence of secondary association determined by genetical equivalence. The purpose of this paper is to extend the original observations and to include in the analysis a consideration of the relative dispositions of marked bivalents that are unrelated genetically.

\section{EXPERIMENTAL METHOD}

In this examination of the secondary pairing of bivalents, use was made of the classification of the chromosomes of Triticum estivum $(2 n=6 x=42)$ into homœologous groups (Sears, 1954; Okamoto, 1962). Homœologous chromosomes are genetically and structurally equivalent members of the three basic genomes which together constitute the complement of this allohexaploid species. They presumably owe their relationship to their common origin from the same chromosome of a single ancestral diploid species. However, in the hexaploid wheats they do not synapse at prophase of meiosis because of the activity of a genetic system, associated with chromosome ${ }_{5} \mathrm{~B}$, that alters the specificity of synapsis so that only fully homœologous partners pair (Riley and Chapman, I958; Riley, I960b; Riley and Kempanna, 1963). Homœologous bivalents might thus be expected to undergo secondary pairing at metaphase provided that the phenomenon is dependent upon the genetic relationship of the participants.

Consequently the purpose of the investigation was to compare the relative positions on the first metaphase plate of pairs of marked bivalents that were either homœeologous or non-homœologous. Two bivalents were simultaneously marked in hybrids produced by crossing together lines in which known, but different, chromosomes were disomic for a telocentric condition and were completely deficient for the non-telocentric arm. In the derivatives of such crosses two pairs of chromosomes consisted of one telocentric and one normal partner. The telocentric and normal partners paired, at meiosis, to form heteromorphic rod bivalents, the relative positions of which could be readily scored at first metaphase (Plate I, fig. 3, Plate II, figs. I, 2 and 3 ).

First metaphase cells with strictly linear alignments of bivalents were scored by recording the numbers of unmarked bivalents that intervened between the marked heteromorphic bivalents. The number of interveners was thus used as a measure of the proximity of the two marked pairs.

This method of scoring is artificial in that the original two dimensional pattern of the metaphase plate is represented unidimensionally. However, it is unlikely that the squashing, used in the preparation of the slides, which was responsible for the linear arrangements would give rise to systematic distortions of the relative spacings of bivalents. Consequently this means of assessing the relative positions of bivalents seems reasonable, although the scores so obtained clearly do not represent the true distances of separation in the living cell.

The slides used for scoring were permanent Feulgen and proprionic orcein squashes of pollen mother cells fixed in acetic alcohol. Before analysis the slides were coded in order to avoid personal bias in scoring. A total of 150 cells were analysed from one plant each for every combination of two marked bivalents. The plants from which these cells were taken were grown together under similar glasshouse conditions.

\section{MATERIAL}

The plants used in the present work were all derivatives of Triticum estivum emend. Thell. ssp. vulgare MacKey variety Chinese Spring. All six lines were intercrossed in which the chromosomes of homœologous group I and homœologous 
group 7 were separately ditelocentric. The bivalents marked in the crosses by the inclusion of one telocentric chromosome were thus $\mathrm{IA}, \mathrm{IB}, \mathrm{ID}, 7 \mathrm{~A}, 7 \mathrm{~B}$ and $7 \mathrm{D}$. In these designations of the chromosomes the number represents the homœologous group and the letter the genome, to which they belong.

Of the 15 possible combinations, with two heteromorphic bivalents, 14 were available-the missing hybrid being that in which chromosomes $7 \mathrm{~A}$ and ${ }_{7} \mathrm{D}$ were marked. The combinations available resulted from the following crosses:-

I. Within homcologous groups

ditelocentric IB $\times$ ditelocentric $\mathrm{A}$ ditelocentric $\mathrm{I} \mathrm{D} \times$ ditelocentric IA ditelocentric $\mathrm{I} \mathrm{D} \times$ ditelocentric I $\mathrm{B}$ ditelocentric $7 \mathrm{~B} \times$ ditelocentric $7 \mathrm{~A}$ ditelocentric $7 \mathrm{D} \times$ ditelocentric $7 \mathrm{~B}$

2. Between homœologous groups

ditelocentric $7 \mathrm{~A} \times$ ditelocentric IA ditelocentric $7 \mathrm{~A} \times$ ditelocentric $\mathrm{IB}$ ditelocentric $7 \mathrm{~A} \times$ ditelocentric $\mathrm{ID}$ ditelocentric $7 \mathrm{~B} \times$ ditelocentric IA ditelocentric $7 \mathrm{~B} \times$ ditelocentric $\times \mathrm{B}$ ditelocentric $7 \mathrm{~B} \times$ ditelocentric $\times \mathrm{D}$ ditelocentric $7 \mathrm{D} \times$ ditelocentric $\mathrm{IA}$ ditelocentric $7 \mathrm{D} \times$ ditelocentric $\mathrm{IB}$ ditelocentric $7 \mathrm{D} \times$ ditelocentric $\times \mathrm{D}$

\section{THE BEHAVIOUR OF ROD BIVALENTS}

The marked bivalents employed in this work included one telocentric chromosome so that they were all rods-chiasma formation being possible in only one arm. Since the shapes of the rod bivalents might have caused similar and systematic modifications of their positions on the metaphase plate, it was necessary to ascertain whether rod bivalents are randomly distributed. Three plants were therefore examined in which a single bivalent was marked. In these three plants chromosomes $7 \mathrm{~B}$, ID and IA respectively were marked by being heteromorphic, telocentric-complete.

The positions of the single heteromorphic rod bivalent was scored in 50 linear equatorial cells, in preparations made from each plant (plate I, fig. 2). The 2 I possible positions of the marked bivalent were divided into two parts each of ten positions. These were both numbered I to Io counting inwards from each extremity of the cell, and the central position was II. The probabilities of the marked bivalent occurring in positions $I$ to ro were equal and were twice that of its occurring in position I I, provided that the distribution along the plate was random.

A contingency test on the scores for the position of the marked bivalents showed that the data for the three plants were homogeneous $\left(\chi_{(10)}^{2}=\mathrm{I} 7 \cdot 80, \mathrm{P}=0 \cdot \mathrm{I}-\mathrm{0}^{\circ} 05\right)$, and the data were therefore summed. A test of the summed data showed that there were no significant difference from the random expectation $\left(\chi_{(5)}^{2}=3.75, \quad \mathrm{P}=0.7-0.5\right)$ (table I). 
Consequently there are apparently no influences that disturb the positioning of bivalents simply because they are rod-shaped. It was therefore reasonable to infer that any divergence of the relative spacings of two marked rod bivalents from the random expectation was due to their interacting with each other or with unmarked bivalents in assuming their positions on the plate. It was also reasonable to

TABLE I

The frequency distribution of cells with different positions of a single marked rod bivalent, compared with the random expectations

\begin{tabular}{|c|c|c|c|}
\hline \multirow{2}{*}{$\begin{array}{l}\text { Position on } \\
\text { the plate }\end{array}$} & \multicolumn{2}{|c|}{ Cells } & \multirow{2}{*}{$x^{2}$} \\
\hline & Observed & $\begin{array}{l}\text { Random } \\
\text { expectation }\end{array}$ & \\
\hline I & I5 & $14.29 ! *$ & \\
\hline 2 & 19 & $14.29\}^{\circ}$ & 1.03 \\
\hline 3 & 14 & $14 \cdot 29\} *$ & 0.04 \\
\hline 4 & 15 & $14.29\}^{\top}$ & 0.04 \\
\hline 5 & 12 & $14.29\} *$ & 0.45 \\
\hline 7 & $\begin{array}{l}13 \\
\text { II }\end{array}$ & $\begin{array}{l}14.29\} \\
14.29 ! *\end{array}$ & \\
\hline 8 & II & $14.29\}^{*}$ & $\mathrm{I} \cdot 5 \mathrm{I}$ \\
\hline 9 & 17 & 14.29 & $0.5 \mathrm{I}$ \\
\hline Io & 14 & $14.29\}_{*}$ & 0.21 \\
\hline II & 9 & $7 \cdot 14)^{*}$ & 0.21 \\
\hline Total & I $5^{\circ}$ & I $50 \cdot 00$ & $3 \cdot 75$ \\
\hline
\end{tabular}

* These classes were combined in testing the homogeneity of the three sets of data which have been pooled in the present table.

$$
\Sigma \chi_{(5)}^{2}=3.75, P=0.7-0.5 .
$$

conclude that differences in the relative distribution of two marked homoologous bivalents, compared with that of two marked nonhomœologous bivalents, were due to the occurrence of different interactions.

\section{THE RELATIVE POSITIONS OF PAIRS OF MARKED BIVALENTS}

\section{(i) Homcologues}

The distributions of cells to the classes with from o to I 9 intervening bivalents were found to be homogeneous in the five samples, of $15^{\circ}$ cells each, obtained from the plants carrying two marked homœologous bivalents $\left(\chi_{(56)}^{2}=62.2 \mathrm{I}, \mathrm{P}=0.2-0.1\right)$. Consequently the data for all five combinations were summed and tested against the frequencies expected from a random distribution (table 2). The random expectation was calculated from a generalised formula $\frac{2(n-\mathrm{I}-r)}{n(n-\mathrm{I})}$, where $n$ 
is the total number of bivalents and $r$ is the number of intervening bivalents. The random distribution is a straight line which in the present case, where $n=2 \mathrm{I}$ and $r=0 \ldots \mathrm{I} 9$, runs from a frequency of $0 \cdot 0952$ with no interveners to $0 \cdot 0048$ with 19 interveners (text-fig. I).

TABLE 2

The frequency distribution of cells with various numbers of unmarked bivalents intervening between two marked homeologous bivalents

\begin{tabular}{|c|c|c|c|}
\hline \multirow{2}{*}{$\begin{array}{c}\text { Intervening } \\
\text { bivalents }\end{array}$} & \multicolumn{2}{|c|}{ Cells } & \multirow{2}{*}{$x^{2}$} \\
\hline & Observed & $\begin{array}{c}\text { Random } \\
\text { expectation }\end{array}$ & \\
\hline 0 & 120 & $71 \cdot 40$ & \\
\hline I & 80 & 67.87 & $2 \cdot 16$ \\
\hline 2 & 66 & 64.27 & 0.05 \\
\hline 3 & 45 & $60 \cdot 67$ & 4.05 \\
\hline 4 & 44 & 57.05 & $3 \cdot 03$ \\
\hline 5 & $5^{i}$ & 53.55 & 0.12 \\
\hline 6 & 44 & $50 \cdot 02$ & 0.73 \\
\hline 7 & $4^{2}$ & $4^{6 \cdot} 4^{2}$ & 0.42 \\
\hline 8 & 42 & $42 \cdot 90$ & 0.00 \\
\hline 9 & 27 & 39.30 & $3 \cdot 85$ \\
\hline 10 & $2 I$ & $35 \cdot 70$ & $6 \cdot 05$ \\
\hline II & 24 & $3^{2 \cdot 17}$ & $2 \cdot 08$ \\
\hline 12 & 27 & 28.57 & 0.09 \\
\hline 13 & 19 & $24 \cdot 97$ & $I \cdot 43$ \\
\hline 14 & 18 & $21 \cdot 45$ & 0.56 \\
\hline I5 & 13 & 17.85 & $\mathrm{I} \cdot 3^{2}$ \\
\hline 16 & 24 & $14 \cdot 3^{2}$ & $6 \cdot 53$ \\
\hline 17 & 19 & $10 \cdot 72$ & $6 \cdot 37$ \\
\hline 18 & IO & $\begin{array}{l}7.20 \mid * \\
3.60\end{array}$ & $16 \cdot 13$ \\
\hline 19 & 14 & 3.001 & \\
\hline Total & $75^{\circ}$ & $750 \cdot 00$ & $88 \cdot 05$ \\
\hline
\end{tabular}

* Combined to increase the expectation

$$
\Sigma \chi_{(18)}^{2}=88 \cdot 05, \mathrm{P}=<0.001 \text {. }
$$

The deviation from random was highly significant $\left(\chi_{(18)}^{2}=88 \cdot 05\right.$, $\mathbf{P}=<0.001$ ) although the general shape of the curve resembled the random distribution - cells with fewer interveners being more common (text-fig. I). The greatest deviations from the random expectation occurred at the extremes of the distribution in the classes with no interveners or with 18 or 19 interveners. At both ends of the distribution the observed frequencies were higher than would have been expected had the spacings of the marked bivalents been random. The large excess with marked homœologues immediately adjacent suggests the operation of secondary pairing determined by genetical relationships, but there is no obvious explanation for the excesses observed at 


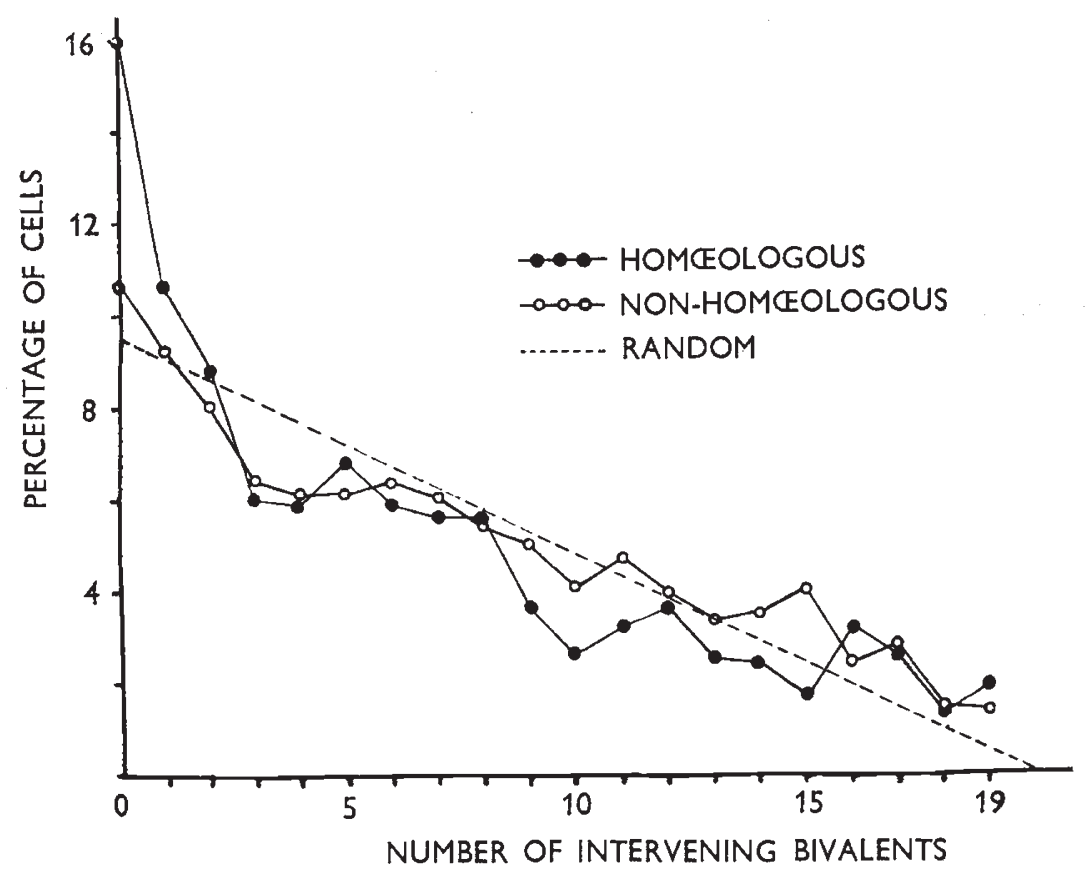

TEXT-FIG. I.-The distribution of cells with from o to 19 unmarked bivalents intervening between two marked bivalents.

the tail of the distribution. To examine these problems further it is necessary to consider the relative spacing of marked non-homœologous bivalents.

\section{(ii) Non-homæeologues}

The distribution of cells with from o to 19 bivalents intervening between marked non-homœologous bivalents were statistically homogeneous $\left(\chi_{(128)}^{2}=105.36, P=0.9\right)$ in the samples, each of 150 cells, of the nine different pair-wise combinations examined. The data for all the non-homœologous combinations were therefore summed and tested against the random expectation (table 3). They were significantly different from random $\left(\chi_{(18)}^{2}=69.62, \mathrm{P}=<0 \cdot 001\right)$ but, in contrast to the data for pairs of marked homœologues, the deviation was almost entirely attributable to excesses observed at the tail of the distribution, especially in the 17 and $18-19$ intervener classes (textfig. I).

The absence of any deviation in the class with immediately adjacent marked bivalents indicates that different forces determine the relative orientation of non-homœologous and homœologous bivalents. Whereas, apparently similar causes result in pairs of bivalents, of both categories, being more widely separated than would be expected if they congressed independently. However, direct comparison of the two sets of data is necessary to display the reality of these contrasts and similarities. 
TABLE 3

The frequency distribution of cells with various numbers of unmarked bivalents intervening between two marked non-homcologous bivalents

\begin{tabular}{|c|c|c|c|}
\hline \multirow{2}{*}{$\begin{array}{c}\text { Intervening } \\
\text { bivalents }\end{array}$} & \multicolumn{2}{|c|}{ Cells } & \multirow{2}{*}{$x^{2}$} \\
\hline & Observed & $\begin{array}{l}\text { Random } \\
\text { expectation }\end{array}$ & \\
\hline o & 1 36 & $128 \cdot 52$ & 0.44 \\
\hline I & 124 & $122 \cdot 17$ & 0.03 \\
\hline 2 & 107 & $115 \cdot 69$ & 0.65 \\
\hline 3 & 86 & 109.20 & 4.94 \\
\hline 4 & 82 & $102 \cdot 87$ & 4.23 \\
\hline $\begin{array}{l}5 \\
6\end{array}$ & $\begin{array}{l}82 \\
85\end{array}$ & $\begin{array}{l}96 \cdot 29 \\
90 \cdot 04\end{array}$ & $\begin{array}{l}2 \cdot 15 \\
0 \cdot 28\end{array}$ \\
\hline 7 & $8 \mathrm{r}$ & $\begin{array}{l}90.04 \\
83.56\end{array}$ & 0.79 \\
\hline 8 & 73 & $77 \cdot 22$ & 0.23 \\
\hline 9 & 68 & $70 \cdot 74$ & 0.11 \\
\hline 10 & $5^{6}$ & $64 \cdot 26$ & $1 \cdot 06$ \\
\hline I I & 64 & 57.90 & 0.64 \\
\hline 12 & 53 & $5^{1} \cdot 43$ & 0.05 \\
\hline 13 & 44 & 44.95 & 0.02 \\
\hline 14 & 47 & $3^{8 \cdot 61}$ & $1 \cdot 82$ \\
\hline 15 & 54 & $32 \cdot 03$ & $14 \cdot 89$ \\
\hline 16 & 32 & $25 \cdot 7^{8}$ & $\mathrm{I} \cdot 50$ \\
\hline 17 & $3^{8}$ & $19 \cdot 30$ & 18.09 \\
\hline $\begin{array}{l}18 \\
19\end{array}$ & $\begin{array}{l}19 \\
19\end{array}$ & $\left.\begin{array}{r}12.9^{6} \\
6.4^{8}\end{array}\right\} *$ & $17 \cdot 72$ \\
\hline & & & \\
\hline Total & 1350 & $1350 \cdot 00$ & $69 \cdot 62$ \\
\hline
\end{tabular}

* Combined to increase the expectation

$$
x_{(18)}^{2}=69.62, P=<0.001
$$

(iii) Homœologues and non-homœologues compared

The frequency distributions, for the intervention of unmarked bivalents between marked homœologous and between marked nonhomœologous bivalents, were shown to be significantly different $\left(\chi_{(19)}^{2}=36 \cdot 18, P=0.01\right)$ in a $2 \times 20$ contingency test (table 4$)$. Moreover, by far the greatest difference between the two sets of data resulted from homœologues lying immediately adjacent more often than non-homœologues. This behaviour is further emphasised by the highly significant $2 \times 2$ contingency test based on the classification into homœologues or non-homœologues and into o interveners or I-I 9 interveners $\left(\chi_{(1)}^{2}=13.82, \mathrm{P}=<0.001\right)$. Indeed there would be no significant difference between homœologues and non-homœologues were the class with o interveners excluded. From this evidence it can be concluded that secondary pairing genuinely occurs between bivalents with genetically and structurally similar chromosomes. In addition an interaction either between the two marked bivalents, or 
TABLE 4

Comparison of, and contingency test on, the data for the distribution of cells with various numbers of unmarked bivalents intervening between two marked homoologous and two marked non-homeoologous bivalents

\begin{tabular}{|c|c|c|c|c|}
\hline \multirow{2}{*}{$\begin{array}{l}\text { Intervening } \\
\text { bivalents }\end{array}$} & \multicolumn{3}{|c|}{ Cells } & \multirow{2}{*}{$\chi^{2}$} \\
\hline & $\begin{array}{c}\text { Marked } \\
\text { homoeologues }\end{array}$ & $\begin{array}{c}\text { Marked } \\
\text { non-homœologues }\end{array}$ & Total & \\
\hline 0 & 120 & I 36 & 256 & 13.90 \\
\hline I & 80 & I 24 & 204 & 1.09 \\
\hline 2 & 66 & 107 & 173 & $0.4^{2}$ \\
\hline 3 & 43 & 86 & 131 & 0.11 \\
\hline 4 & 44 & 82 & 126 & 0.03 \\
\hline 5 & $5^{1}$ & 82 & I 33 & 0.40 \\
\hline$\breve{6}$ & 44 & 85 & 129 & 0.14 \\
\hline 7 & $4^{2}$ & $8 \mathrm{I}$ & 123 & 0.14 \\
\hline 8 & 42 & 73 & 115 & 0.03 \\
\hline 9 & 27 & 68 & 95 & $2 \cdot 20$ \\
\hline 10 & $2 \mathrm{I}$ & $5^{6}$ & 77 & $2 \cdot 39$ \\
\hline I I & 24 & 64 & 88 & $2 \cdot 74$ \\
\hline 12 & 27 & 53 & 80 & 0.13 \\
\hline 13 & 19 & 44 & 63 & 0.84 \\
\hline 14 & 18 & 47 & 65 & $1 \cdot 82$ \\
\hline 15 & 13 & 54 & 67 & $7 \cdot 76$ \\
\hline 16 & 24 & 32 & 56 & I $\cdot 24$ \\
\hline 17 & 19 & $3^{8}$ & 57 & 0.14 \\
\hline 18 & 10 & 19 & 29 & 0.02 \\
\hline 19 & 14 & 19 & 33 & 0.64 \\
\hline Total & 750 & $135^{\circ}$ & 2100 & $3^{6 \cdot 18}$ \\
\hline
\end{tabular}

between each marked bivalent and unmarked bivalents, causes the marked pairs to be widely spaced more often than would occur if they orientated independently.

\section{DISCUSSION}

The present evidence confirms the earlier observations of Riley ( $1960 a$ ), and shows that there is secondary association between genetically related bivalents in T. estivum. Moreover there is no association between genetically unrelated bivalents. The secondary association cannot be dependent upon similarities in the sizes of the associating bivalents since differences in the sizes of wheat chromosomes are not primarily related to homœologous groupings (Morrison, 1953; Sears, 1954). Indeed the differences in size are in any case probably too small to cause a non-random distribution of bivalents - the ratio of the largest to the smallest first metaphase chromosome being approximately I:I.6 (Sears, 1954). Secondary association must therefore be dependent upon attractions determined by residual homology or homœology. 
The precise nature of this secondary affinity cannot be ascertained from the present results, which do no more than show the reality of the phenomenon, but two alternative causes can be visualised. It may be, according to one hypothesis, that at zygotene all six homœologous chromosomes are attracted together but that primary pairing only takes place between fully homologous partners. Homœologues would then be neighbours throughout prophase and the relics of the prophase attraction would be revealed as secondary association at first metaphase.

Alternatively secondary association may result from quite distinct forces of attraction that occur during the congression of bivalents onto the first metaphase plate. This hypothesis is made less attractive by the absence of any contact between secondarily associated bivalents. To accommodate this behaviour it would be necessary to propose a model in which forces of attraction operated over long distances to bring homœologous bivalents together, but that no contact was made because over shorter distances these forces either ceased to operate or were opposed by forces of repulsion.

A less elaborate hypothesis is required to explain secondary association as the residual expression of prophase attraction since, in wheat, the primary synapsis of homœeologues is precluded by the genetic activity of chromosome 5B (Riley, I96ob; Riley and Kempanna, I963). Consequently we can visualise that the failure of homœologues to make contact is due to this activity and the problem of attraction without contact is explained by systems already known. Moreover, it may well be that in all bivalent-forming allopolyploid species the causes, whatever their nature, of the absence of homœologous synapsis, following prophase attraction, similarly result in secondary association.

The excesses of the classes with widely separated marked bivalents over the random expectation may be viewed in two ways. If the excess reflects the true spatial distribution in living cells, the insertion of secondarily associated groups could have increased the separation of marked bivalents, whether non-homœologous or homœologous, which display no association in the cells concerned. By contrast the excess may merely be an artifact caused by the splitting of the spindle during squashing, at a point where two rod bivalents were adjacent, and by the opening of the plate so that the rods lie at opposite extremes. At the present stage, however, the wide separation of marked bivalents must be treated as an interesting but unresolved occurrence.

A comment should be made about the effects on secondary association of the structural conditions used to mark bivalents in this work. Glearly the amount of genetically equivalent material in homœologous bivalents is reduced by the incorporation of one telocentric chromosome in each. The reduction will be greater if the deficient arms are not, than if they are, equivalent. In either case the effect might be to lower the affinity of bivalents marked by telocentric components, so that the secondary association demonstrated in the present work may be less than that which occurs between normal homœologous bivalents. 
However, the ability to estimate the strength of the forces involved in secondary association, in the way used in the present work, will provide a new means of evaluating the effects of environmental variables on chromosome pairing. The response of chiasma frequency to environmental differences has been extensively studied by a number of investigators but it is clearly not possible to determine to what extent induced variations in this character are due to alterations either in chiasma formation or to alterations in chromosome pairing. The study of secondary association, which is dependent upon pairing attractions without chiasma formation, should permit discrimination between the two components of the overall characters-allowing direct measurements of the effects of environmental variables on chromosome pairing.

\section{SUMMARY}

In a range of plants of the $2 \mathrm{I}$-bivalent forming hexaploid wheat, Triticum astivum $(2 n=6 x=42)$, two bivalents were simultaneously marked by the inclusion of one telocentric chromosome in each. The two marked bivalents were either genetically corresponding, homœologous, members of different genomes, or were genetically unrelated non-homœologues.

The relative positions of the two marked bivalents on linear first metaphase plates were expressed in terms of the numbers of unmarked bivalents by which they were separated. Homœologous bivalents were found to be immediately adjacent more frequently than nonhomœologous bivalents. It was thus possible to demonstrate quantitatively that the phenomenon of secondary association is dependent upon the genetic relationships of the associated bivalents.

Acknowledgments.-The financial assistance of the Government of Mysore (India) to one of us (C.K.) is gratefully acknowledged. It is a pleasure to thank our colleagues Mr Colin N. Law, Mr Victor Chapman and Dr Gordon Kimber for their generous assistance. Valuable technical help was given by Mr T. E. Miller and Mr H. A. Torrens.

\section{REFERENCES}

DARlington, C. D., AND MOfFet, A. A. I930. Primary and secondary chromosome balance in Pyrus. 7. Genet., 22, I 29-1 $5 \mathrm{I}$.

gustafsson, A. 1934. Primary and secondary association in Taraxacum. Hereditas, 20, I-3I.

HEILBORN, O. 1936. The mechanism of so-called secondary association between chromosomes. Hereditas, 22, 167-188.

LAWRENCE, w. J. G. I93I. The secondary association of chromosomes. Cytologia, $2,352-384$.

MORrison, J. w. 1953. Chromosome behaviour in wheat monosomics. Heredity, 7, 203-2I7.

NANDI, H. K. 1936. The chromosome morphology, secondary association and origin of cultivated rice. 7. Genet., 33, 31 5-336.

охамото, м. 1962. Identification of the chromosomes of common wheat belonging to the $\mathrm{A}$ and $\mathrm{B}$ genomes. Canad. 7. Genet. Cytol., 4, 31-37. 


\section{Plate 1}

Photomicrographs of first metaphase of meiosis in pollen mother cells of $T$. astivum variety Chinese Spring.

Fig. I. - From a euploid individual showing the suggestion of secondary association which is sometimes displayed. In this cell there are possibly five groups each of three bivalents indicative of the secondary association of homoeologues.

Fig. 2.-From a 42-chromosome individual with one telocentric chromosome. Such plants were used to score the distribution of a single, marked, rod bivalent on the plate. In this case the heteromorphic rod is at position 6 .

FIG. 3.-From an individual with two heteromorphic, telocentric-complete, rod bivalents. In this case there are 15 unmarked intervening bivalents. 


\section{Plate II}

Photomicrographs of first metaphase of meiosis in pollen mother cells of plants of $T$. astivum variety Chinese Spring with two marked, telocentric-complete, bivalents.

Figs. I and 2.-One unmarked bivalent intervenes between the marked heteromorphic bivalents.

Fig. 3.-Nineteen unmarked bivalents intervene between the marked heteromorphic bivalents. 
ti

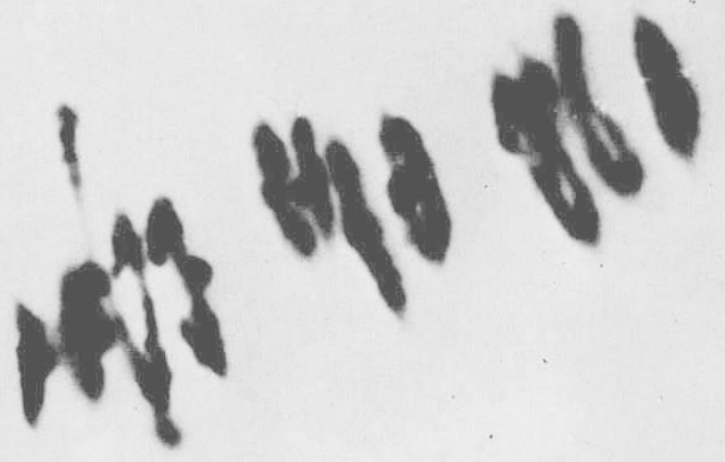

(1)

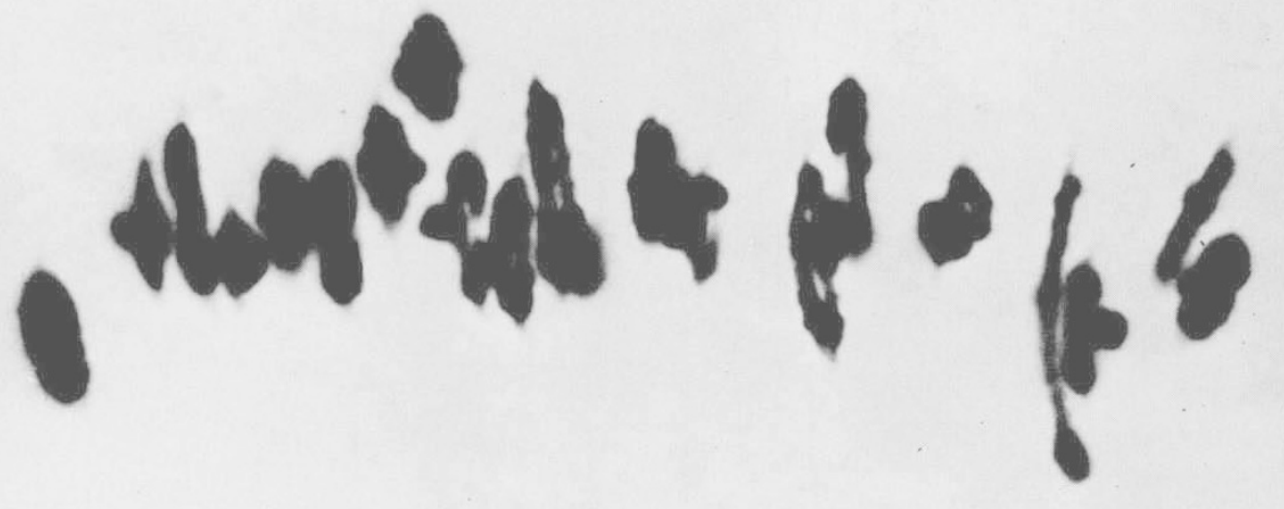

(2)

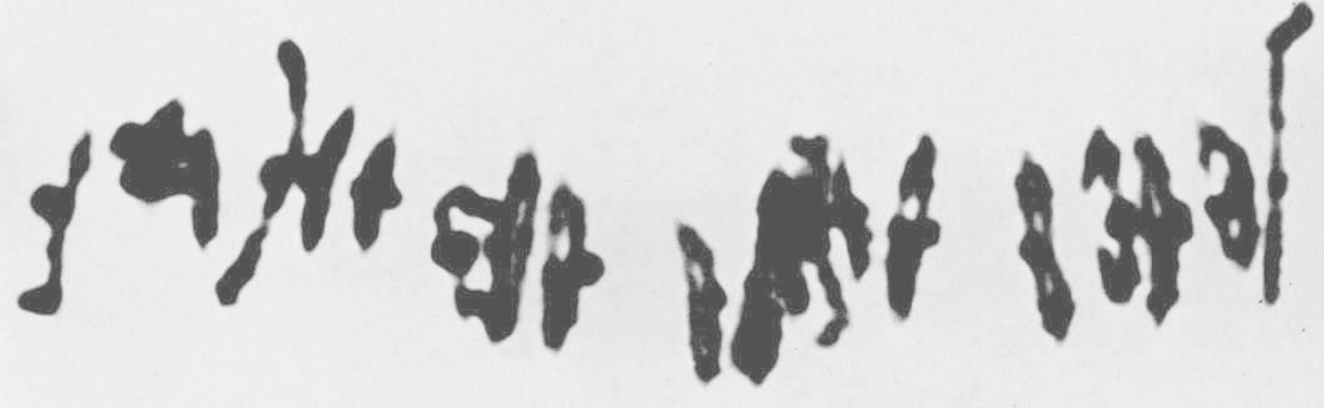

(3) 
RILEY, R. I960a. The secondary pairing of bivalents with genetically similar chromosomes. Nature, Lond., 185, 75 I-752.

RILEY, R. I960 $b$. The diploidisation of polyploid wheat. Heredity, 15, 407-429.

RILEY, R., AND GHAPMAN, v. I958. Genetic control of the cytologically diploid behaviour of hexaploid wheat. Nature, Lond., 182, 713-715.

RILEY, R., AND KEMPANNA, C. 1963. The homœologous nature of the non-homologous meiotic pairing in Triticum estivum deficient for chromosome $\mathrm{V}\left({ }_{5} \mathrm{~B}\right)$. Heredity, $18,287-306$.

sakaI, K. 1935. Chromosome studies in Oryza sativa L. I. The secondary association of the meiotic chromosomes. 7ap. 7. Genet., 11 , 145-156.

SEARS, E. R. 1954. The aneuploids of common wheat. Res. Bul. Mo. Agric. Exp. Sta., 572.

THOMAS, P. T., AND REVELL, S. H. I946. Secondary association and heterochromatic attraction. I. Cicer arietinum. Ann. Bot., 38, I59-I64. 